\title{
Original Research \\ A pharmacovigilance study in the department of medicine of a university teaching hospital
}

Himanshu SHARMA, Mohammed AQIL, Faisal IMAM, Mohammad S. ALAM, Prem KAPUR, Krishna K. PILLAI.

\begin{abstract}
The aim of the present study was to monitor adverse drug reactions (ADRs) in the Medicine out patient department (OPD) of a University Teaching Hospital.

Method: A prospective evaluation of the ADRs reported in the Department of Medicine of our University Teaching Hospital over a period of 4months was conducted.

Results: During the study period, a total of 600 patients visited the Medicine OPD and 122 ADRs were reported. Out of 122 reports that were identified, a higher percentage of ADRs in males $(52.4 \%)$ was observed as compared to females (47.5\%). Of the 122 ADRs, 50 were found to be mild (41.0\%), 49 moderate (40.2\%), and 23 severe (18.2\%). A total of 71 (58.0\%) ADRs were observed in patients receiving 4 or more medications concurrently. Conversely 46 (37.7\%) ADRs were detected in patients using 3 or less medicines. The largest number of reports were associated with antihypertensive therapy (39.3\%), followed by antimicrobials (31.1\%) and antidiabetics (10.7\%). Amongst the organ systems affected, gastrointestinal ADRs constituted a major component $(24.7 \%)$ followed by skin reactions (22.2\%). On causality assessment, nearly $29.5 \%$ ADRs were considered as probable, $33.6 \%$ possible and $6.6 \%$ could not be categorised and were placed under unassessable.

Conclusion: The present work is the maiden pharmacovigilance study conducted at our university teaching hospital. The data presented here will be useful in future, long term and more extensive ADR monitoring in the hospital and in
\end{abstract}

\footnotetext{
Himanshu SHARMA. M.Pharm. Research Associate. Ranbaxy Research Laboratories.

Gurgaon, Haryana (India).

Mohammed AQIL. M.Pharm, PhD. Assistant Professor. Department of Pharmaceutics,

Faculty of Pharmacy, Hamdard University. New Delhi (India).

Faisal IMAM. M.Pharm. Research Scholar. Department of Pharmacology, Faculty of Pharmacy, Hamdard University. New Delhi (India).

Mohammad S. ALAM. M.Pharm. Lecturer. Department of Pharmacology, Faculty of Pharmacy, Hamdard University. New Delhi (India).

Prem KAPUR. MBBS, MD. Consultant Physician \&

Medical Superintendent. Majeedia Hospital, Hamdard University. New Delhi (India).

Krishna K. PILLAl. M.Pharm, PhD. Professor\& Head, Department of Pharmacology,

Faculty of Pharmacy, Hamdard University. New Delhi (India).
}

promotion of rational prescribing and drug use in the hospital.

\author{
Keywords: Adverse Drug Reaction Reporting \\ Systems. India.
}

\section{RESUMEN}

El objetivo del presente estudio fue monitorizar las reacciones adversas medicamentosas (RAM) en el departamento de consultas externas (DCE) de un Hospital Universitario.

Método: Se realizó una evaluación prospectiva del as RAM comunicada sen el Departamento de Medicinad e nuestro Hospital Universitario durante un periodo de 4 meses.

Resultados: Durante el periodo de estudio, 600 pacientes visitaron el DCE y en 122 se comunicaron RAM. De las 122 comunicaciones, se observó un mayor porcentaje de hombres $(52,4 \%)$ que de mujeres $(47,5 \%)$. De las 122 RAM, 50 fueron leves $(41,0 \%), 49$ moderadas $(40,2 \%)$ y 23 graves $(18,2 \%)$. 71 RAM $(58,0 \%)$ se observaron en pacientes con 4 o más medicamentos simultáneos. Mientras que $46(37,7 \%)$ RAM se observaron en pacientes con 3 o menos medicamentos. El mayor número de comunicaciones estaba asociado a tratamientos antihipertensivos $(39,3 \%)$, seguidos de antimicrobianos $(31,1 \%)$ y antidiabeticos $(10,7 \%)$. Entre los órganos y sistemas afectados, el gastrointestinal constituía el mayor $(24,7 \%)$ seguido del as reacciones cutáneas $(22,2 \%)$. Ene $n$ análisis de causalidad, casi el $29,5 \%$ de las RAM se consideraron como probables, el 33,6\% como posibles y el $6,6 \%$ no pudieron clasificarse por ser invalorables.

Conclusión: El presente trabajo es el principal estudio de farmacovigilancia realizado en nuestro hospital universitario. Los datos aquí presentados serán útiles para la monitorización futura y más intensa de RAM en el hospital y para promover la prescripción y el uso racionales en el hospital

Palabras clave: Sistemas de comunicación de reacciones adversas. India.

\section{(English)}

\section{INTRODUCTION}

According to WHO'S definition an Adverse Drug Reaction (ADR) is a response to a drug that is 
noxious and unintended, and occurs at doses normally used in human for the prophylaxis, diagnosis, and treatment of disease, or for modification of physiological function.,

Lazarous et al. ${ }^{3}$ estimated that ADRs were the fourth to sixth largest cause of death in the United States. There are few recent reports on epidemiology of ADRs. ${ }^{4}$ In United Kingdom most of the studies were performed in the previous two decades and were restricted to specific areas such as monitoring of ADRs in geriatric patients. ${ }^{5-12}$ The largest UK study was based on retrospective review of case reports and gave poor documentation. ${ }^{13}$

The detection of adverse drug reactions (ADRs) has become increasingly significant because of introduction of a large number of potent toxic chemicals as drugs in the last two or three decades. $\mathrm{WHO}$ has intervened seriously in the matter and established an international adverse drug reactions monitoring centre at Uppsala, Sweden which is collaborating with national monitoring centres in around 70 countries. ${ }^{14}$

In India there are very few active ADRs monitoring centres and a lot of effort is required in order to collect ADR data which may generate from safety surveillance of billions of therapeutically active substances either alone or in combinations.

We performed a prospective analysis of ADRs caused by medicines prescribed in the department of medicine in the Majeedia Hospital, attached to Hamdard University, situated in south Delhi locality to define prevalence and to assess causality of these reactions.

\section{METHODS}

ADR monitoring at our university teaching hospital was done from December 2003 to March 2004. Patients attending Medicine out patient department (OPD) irrespective of age and sex were included in the study. Patients taking more than ten prescription drugs at a time were not included in the study. All mentally retarded, drug addicts, unconscious and patients unable to respond to verbal questions were also excluded from the study.

An informed consent was taken from the patients for participating in the study. The study was initiated after the approval of the study protocol by Hamdard University Institutional Review Board.

The adverse drug reactions experienced by the patients were documented on ADR monitoring form designed on the basis of WHO guidelines. ${ }^{15}$ The form includes data like age, sex, demographic details, past medical history, present drug treatment, description of adverse drug reaction, its assessment and treatment for the drug reaction.

Monitoring was done by following two methods: Intensive ADR monitoring of patients in Medicine OPD by a registered pharmacist and voluntary reporting of ADRs by physician.
Causality assessment of adverse events was done according to the causality categories recommended by the WHO Uppsala Monitoring Center. ${ }^{13}$

\section{RESULTS}

During the 4 months study period, a total of 600 patients visited the Medicine OPD (Table 1). A total of 122 ADRs were reported in 600 patients. The gender distribution among the patients who experienced ADRs was comparative with males having experienced more number of ADRs as compared to the females (64 versus 58). The frequency of ADRs was maximum (43.4\%) in patients with age group of $25-50$ years; next susceptible age group was that of elderly patients (more than 50 years) with $40.1 \%$ of ADRs. The number of ADRs in less than 25 years age was lowest (14.7\%).

\begin{tabular}{|c|r|r|r|}
\hline \multicolumn{5}{|c|}{ Table 1: Patient Demographics } \\
\hline $\begin{array}{c}\text { Age } \\
\text { (years) }\end{array}$ & \multicolumn{1}{|c|}{ Men } & Women & \multicolumn{1}{|c|}{ Total } \\
\hline $0-10$ & $1(2.90 \%)$ & 0 & $1(0.17 \%)$ \\
\hline $11-20$ & $51(15.04 \%)$ & $22(8.43 \%)$ & $73(12.16 \%)$ \\
\hline $21-30$ & $90(26.55 \%)$ & $67(25.67 \%)$ & $157(26.17 \%)$ \\
\hline $31-40$ & $64(18.88 \%)$ & $63(24.14 \%)$ & $127(21.17 \%)$ \\
\hline $41-50$ & $65(19.17 \%)$ & $50(19.16 \%)$ & $115(19.17 \%)$ \\
\hline $51-60$ & $43(12.68 \%)$ & $37(14.18 \%)$ & $80(13.33 \%)$ \\
\hline $61-70$ & $20(5.90 \%)$ & $16(6.13 \%)$ & $36(6.00 \%)$ \\
\hline $71-80$ & $4(118 \%)$ & $6(2.30 \%)$ & $10(1.67 \%)$ \\
\hline $81-90$ & $1(0.29 \%)$ & 0 & $1(0.17 \%)$ \\
\hline Total & $339(56.50 \%)$ & $261(43.50 \%)$ & $600(100 \%)$ \\
\hline
\end{tabular}

As expected polypharmacy had a major influence on the occurrence of ADRs with a total of 71 $(58.0 \%)$ ADRs observed in patients receiving 4 or more medications concurrently (Table 2). Conversely, 46 (37.7\%) ADRs were detected in patients on 3 or less medicines. The frequency of ADRs associated with different routes of administration was as follows: oral $(n=110)$, parentral $(n=11)$ and topical $(n=1)$.

\begin{tabular}{|c|c|c|}
\hline \multicolumn{3}{|c|}{ Table 2: ADRs associated with Polypharmacy } \\
\hline $\begin{array}{c}\text { Number of } \\
\text { medicines }\end{array}$ & $\begin{array}{c}\text { Number of } \\
\text { ADRs }\end{array}$ & $\begin{array}{c}\text { Percentage } \\
\text { (\%) of ADR }\end{array}$ \\
\hline 1 & 15 & 12.29 \\
\hline 2 & 20 & 16.39 \\
\hline 3 & 11 & 9.02 \\
\hline 4 & 19 & 15.57 \\
\hline 5 & 29 & 23.77 \\
\hline 6 & 12 & 9.84 \\
\hline 7 & 11 & 9.02 \\
\hline Unspecified & 5 & 4.10 \\
\hline
\end{tabular}

The gastrointestinal side effects (e.g. gastritis, dysphasia etc.) were at the top with $24.7 \%$ followed by skin and subcutaneous disorders $(22.2 \%)$. Other main groups were metabolic and nutritional disorders (8.3\%), CNS and neurological disorders (7.4\%). The detailed description of organ systems affected by ADRs is shown in Table 3.

Out of a total number of 122 ADRs, 6 (4.9\%) were classified as certain, e.g. hypersensitivity reaction with intravenous contrast medium, skin reaction with cefotaxime injection, itching and dermatitis with etophylline tablets and hypoglycemia with glibenclamide tablets. Thirty six ADRs (29.5\%) were considered probable e.g. dry cough with enalapril 
and dysphasia with furosemide tablets. Forty one $(33.6 \%)$ were classified as possible e.g. loss of appetite and pain in abdomen with antitubercular medicines and breathlessness with nimesulide and metoprolol. Eight ADRs (6.6\%) could not be categorized and were placed under unassessable category e.g. itching with antitubercular drugs, mental depression with metoprolol, (Table 4).

\begin{tabular}{|l|l|c|c|}
\hline \multicolumn{2}{|l|}{ Table 3: ADR and organ system affected } & $\begin{array}{c}\text { No. of } \\
\text { ADRs }\end{array}$ & $\begin{array}{c}\text { Percentage } \\
\text { of ADRs }\end{array}$ \\
\hline S. No. & Organ system affected by ADR & 4 & 3.3 \\
\hline 1 & Blood and lymphatic system disorders & 2 & 1.6 \\
\hline 2 & Immune system disorders & 5 & 4.2 \\
\hline 3 & Endocrine system disorders & 10 & 8.3 \\
\hline 4 & Metabolism and nutritional disorders & 9 & 7.4 \\
\hline 5 & CNS and Neurological disorders & 1 & 0.8 \\
\hline 6 & Eye disorders & 1 & 0.8 \\
\hline 7 & Ear and labyrinth disorders & 5 & 4 \\
\hline 8 & Cardiac disorders & 11 & 5.1 \\
\hline 9 & Vascular disorders & 30 & 9.1 \\
\hline 10 & Respiratory system disorder & 27 & 24.7 \\
\hline 11 & Gastrointestinal disorders & 1 & 22.2 \\
\hline 12 & Skin and subcutaneous disorders & 1 & 0.8 \\
\hline 13 & Hepato-billiary disorders & 1 & 0.8 \\
\hline 14 & Musculoskeletal, connective tissue and bone disorders & 7 & 0.8 \\
\hline 15 & Reproductive system disorders & & 5.7 \\
\hline 16 & General disorders and administration site condition & 7.7 \\
\hline
\end{tabular}

Of the 122 ADRs, 50 (41.0\%) were found to be mild e.g. cold extremities with atenolol, 49 (40.2\%) moderate e.g. dry cough with ramipril and 23 $(18.2 \%)$ severe e.g. subcutaneous bleeding with carbimazole. Most of the severe ADRs were associated with antitubercular, oral hypoglycemic drugs, insulin and heparin. These were reported more commonly with injectables as compared to oral medications. Ten serious and the life threatening ADRs were also reported e.g. hepatitis with antitubercular medicines and anaphylactic reactions with iopromide (i.v. contrast medium). Drug induced morbidity is an important cause of hospitalization and is associated with significant mortality. Most of the ADRs observed in our study were either mild or moderate (Table 5).

\begin{tabular}{|l|c|}
\hline \multicolumn{2}{|c|}{ Table 4: Causality Assessment of ADRs } \\
\hline \multicolumn{1}{|c|}{ Probability scale } & Number of ADRs \\
\hline Certain & 6 \\
\hline Probable & 36 \\
\hline Possible & 41 \\
\hline Unlikely & 26 \\
\hline Conditional & 5 \\
\hline Unassessable & 8 \\
\hline Total & 122 \\
\hline
\end{tabular}

\begin{tabular}{|c|c|c|}
\hline Group & No. of ADRs & Percentage of ADRs \\
\hline Mild & 50 & $41.0 \%$ \\
\hline Moderate & 49 & $40.2 \%$ \\
\hline Severe & 23 & $18.2 \%$ \\
\hline Total & 122 & $100 \%$ \\
\hline
\end{tabular}

Distribution of ADRs across therapeutic classes was as follows: antihypertensives (39.3\%), antimicrobials (31.1\%), antidiabetics (10.7\%) and NSAIDs (6.7\%). Among the individual drugs, ramipril was associated with maximum cases of ADRs $(6.6 \%)$ followed by amlodipine $(5.7 \%)$ and atenolol (4.1\%). In case of fixed dose drug combinations, isoniazid + rifampicin + ethambutol + pyrazinamide combination was responsible for $13.1 \%$ ADRs.

\section{DISCUSSION}

Number of drug related visits to the OPD was $5.1 \%$ whereas $3.1 \%$ ADRs led to the hospitalization of patients. One reason for the above occurrence could be the concomitant disease conditions in these patients and thus more susceptibility of patients to the adverse effects of medicines.

Although male population had more prevalence of ADRs, the difference was negligible with respect to female population. Previous studies report that the occurrence of ADRs is more common in women. ${ }^{16-}$

17 In our study the majority of ADRs were in 25-50 years age group. The reasons that could be attributed are that the patients of this age group suffered from hypertension and diabetes due to modern sedentary lifestyle. Increased stress in daily life make this age group more prone to hypertension and diabetes. So this age group used more number of medicines and frequently visited the medicine OPD for their regular check-up and complained for drug related adverse events, though most of these adverse events were mild and easily tolerated.

Majority of the ADRs were associated with oral administration of medicines followed by parenteral route. Most of the ADRs with injectable medications were severe. The one topical reaction observed was erythema (localized skin redness) on application of benzyl nicotinate and heparin sodium cream. Gastrointestinal ADRs were most commonly observed with oral medications.

The incidence of adverse drug events is not directly proportional to the number of drugs being taken but increases remarkably as number of drugs rises. Polypharmacy needs to be discouraged for a good number of ADRs results from drug-drug interactions. The Boston Collaborative group (1972) 
reported $36 \%$ ADRs, $6.9 \%$ of which were attributed to drug interactions in a cohort of 10,000 patients. Advancing age, improved economical status has been correlated with an increased use of prescription drugs. ${ }^{19}$ Patients also cannot identify correctly $60 \%$ of their medicines, $40 \%$ of patients received drugs prescribed by two or more physicians, increasing the possibility of drug-drug interactions, $12 \%$ patients take drugs prescribed for someone else and $60 \%$ patients consider their drugs completely safe. These factors must also contribute to the occurrence of drug-induced illness and might be responsible, at least in part, for the frequency of admission to hospitals of patients with adverse reaction to drugs. ${ }^{18}$

Both hypertensive and diabetic patients are predisposed to ADRs and they are at inevitable risk of bad effects of drugs due to sub-optimal functionality of their organ systems. This necessitates careful organ function analysis prior to prescription writing of any medication. One of the essential reasons of wide prevalence of ADRs in hypertensive and diabetic patients is that they are elderly and are often on multiple drug therapy.

In our study, we found gastrointestinal side effects (e.g. gastritis, dysphagia etc.) at the top followed by skin and subcutaneous disorders. Next main groups are metabolic, nutritional, CNS and neurological disorders. Neurological ADRs were at the top of the list of ADRs in previous studies ${ }^{19,20}$ and gastrointestinal ADRs were reported amongst the top three groups of ADRs. ${ }^{19}$

\section{CONCLUSION}

The present work is the maiden pharmacovigilance study conducted at our university teaching hospital. It has provided base line information about the prevalence of ADRs and their distribution amongst different age groups, genders, organ systems affected and therapeutic classes of medicines. The data presented here will be useful in future, long term and more extensive ADR monitoring in the hospital and will be useful in framing policies towards rational use of drugs.

\section{References}

1. WHO international drug monitoring the role of national centres tech rep ser WHO 1972. p. 498.

2. Couper MR and Mehta DK, Eds., In: WHO Model Formulary 2002, 1st Edn., Geneva: World Health Organisation; 2002. 9.

3. Lazarous J, Pomeranz BH, Corey PN. Incidence of adverse drug reactions in hospital patients-a meta analysis of prospective study. JAMA 1998;279:1200-5.

4. Wiffen P, Gill M, Edwards J, Moore A. Adverse drug reactions in hospital patients. A systematic review of the prospective and retrospective studies. Bandolier Extra 2000:June:1-16.

5. Ghose K. Hospital bed occupancy due to drug related problems. J R Soc Med 1980;73:853-7.

6. Gosney M, Tallis R. Prescription of contraindicated and interacting drugs in elderly Patients admitted to hospital. Lancet 1984;ii:564-7.

7. Hurwitz N. Admission to hospital due to drugs. BMJ 1969;i:539-40.

8. Hurwitz N. Predisposing factors in the adverse drug reactions to drugs. BMJ 1969;i:536-9.

9. Hurwitz N, Wade OL. Intensive hospital monitoring of adverse drug reactions to drugs. BMJ 1969;i:531-6.

10. Leach S, Roy SS. Adverse drug reactions: an investigation on an acute geriatric ward. Age Aging 1986;15:241-6.

11. Williamson J, Chopin JM. Adverse reactions to prescribed drugs in the elderly: a multicentre investigation. Age Aging 1980;9:73-80.

12. Lindley CM, Tully MP, Paramsothy V, Tallis RC. Inappropriate medication is a major cause of adverse drug reactions in elderly patients. Age Aging 1992;21:294-300.

13. Smith CC, Bennett PM, Pearce HM, Harrison PI, Reynolds DJ, Aronson JK, et al. Adverse drug reactions in a hospital general medicine unit meriting notification to the Committee on Safety of Medicines. Br J Cln Pharmacol 1996;42:423-9.

14. Kurokawa T, Correa-Nunes AM, Czarnecki A. Guidelines for setting up and running a Pharmacovigilance Centre. Uppsala Monitoring Centre, WHO Collaborating Centre for International Drug Monitoring, Sweden, 2000, p. 4-10.

15. Stephens MBD. The diagnosis of adverse medical events associated with drug treatment. Adverse Drug Reaction Acute Poisoning Rev 1987;1:1-35.

16. Hoddinott BC. Drug reactions and errors in admission on a medical ward. Can Med Assoc J 1967;97:1001-6.

17. Vervloet D, Durham S. ABC of allergies adverse reaction to drugs. BMJ 1998;316:1511-4.

18. Stewart RB, Cluff LE. Studies on the epidemiology of adverse drug reactions: VI. Utilization and interactions of prescription and non prescription drugs in out patients. Johns Hopkins Med J 1971;129:319-31.

19. Gurwitz JH, Field TS, Avorn J, McCormick D, Jain S, Eckler M, Benser M, Edmondson AC, Bates DW. Incidence and preventability of adverse drug events in nursing homes. Am J Med 2000;109:87-94.

20. Peyriere H, Cassan S, Floutard E, Riviere S, Blayac JP, Hillaire-Buys D, Le Quellec A, Hansel S. Adverse Drug Events associated with hospital admission. Ann Pharmacother 2003;37:5-11. 